Spindler KG, Appelt AL, Pallisgaard N, Andersen RF, Jakobsen A (2013) KRASmutated plasma DNA as predictor of outcome from irinotecan monotherapy in metastatic colorectal cancer. Br J Cancer 109: 3067-3072.

Spindler KL, Pallisgaard N, Vogelius I, Jakobsen A (2012) Quantitative cell-free DNA, KRAS, and BRAF mutations in plasma from patients with metastatic colorectal cancer during treatment with cetuximab and irinotecan. Clin Cancer Res 18: 1177-1185.

Taly V, Pekin D, Abed AE, Laurent-Puig P (2012) Detecting biomarkers with microdroplet technology. Trends Mol Med 18: 405-416.
Taly V, Pekin D, Benhaim L, Kotsopoulos SK, Le Corre D, Li X, Atochin I, Link DR, Griffiths AD, Pallier K, Blons H, Bouché O, Landi B, Hutchison JB, LaurentPuig P (2013) Multiplex Picodroplet Digital PCR to Detect KRAS Mutations in Circulating DNA from the Plasma of Colorectal Cancer Patients. Clin Chem 59: $1722-1731$.

Tougeron D, Lecomte T, Pages JC, Villalva C, Collin C, Ferru A, Tourani JM, Silvain C, Levillain P, Karayan-Tapon L (2013) Effect of low-frequency KRAS mutations on response to anti-EGFR therapy in metastatic colorectal cancer. Ann Oncol 24: 1267-1273.

*Correspondence: Dr D Tougeron; E-mail: davidtougeron@hotmail.fr

Published online 11 March 2014

(c) 2014 Cancer Research UK. All rights reserved 0007 - 0920/14

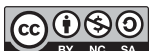

http://creativecommons.org/licenses/by-nc-sa/3.0/

\title{
Response to comment on 'KRAS-mutated plasma DNA as predictor of outcome from irinotecan monotherapy in metastatic colorectal cancer'
}

\author{
K-L G Spindler ${ }^{\star}, 1,2,4$, N Pallisgaard ${ }^{2,3}$, R F Andersen ${ }^{2,3}$ and A Jakobsen ${ }^{1,2}$ \\ ${ }^{1}$ Department of Oncology, Vejle Hospital, Vejle, Denmark; ${ }^{2}$ Danish Colorectal Cancer Group South, Vejle Hospital, Kabbeltoft 25, 7100 Vejle, \\ Denmark and ${ }^{3}$ Department of Biochemistry, Vejle Hospital, Vejle, Denmark
}

Sir,

We were pleased to read the comments (Tougeron et al, 2014)on our recently published data on KRAS mutation detection in plasma, which underline the strong interest these aspects attract.

Cell-free DNA, and tumour mutation detection and quantification in plasma can be discussed from three different but interacting aspects-that is, methodological, biological and clinical. In the comments from our peers, there is a strong biological and methodological focus, whereas in our report of the data, we have chosen to focus on the clinical observations. With the current threshold for mutation detection in our cohort, we found a strong association to outcome in terms of both responses, PFS and OS. However, contrary to the criticism above, we have not definitively concluded that our observations are predictive (hence, the title predictive of 'outcome'), as (as also stated in our concluding remarks) randomized trials are clearly needed to clarify this.

In general, we agree with most of the comments above, all of that are highly relevant from a biological and methodological view.

Of note, the method used in our lab has been developed and refined to a detection level far beyond the reported $0.1 \%$ referred to by the authors. The detection sensitivity varied between 0.03 and $0.0005 \%$ depending on the type of mutation detected, 12asp (1/200000, $0.0005 \%)$, 12Cys (1/200000, $0.0005 \%)$, 12 ser $(1 / 7000,0.014 \%), 13$ asp $(1 / 3000,0.033 \%)$, 12ala (1/100000, $0.0010 \%)$, $12 \mathrm{val}(1 / 200000,0.0005 \%), 12 \arg (1 / 200000,0.0005 \%)$, respectively. However, as also stated above that regardless of the assay, the sensitivity may be determined by the concentration of DNA because of the generally low amount in plasma. Whereas a reliable method with a high sensitivity is needed for mutation detection, it can also be argued that there is a clinical as well as a subclinical detection level. In other words, the importance of the mutations depends on a certain threshold, and that detection of subclinical levels may be less relevant from a clinical point of view.

It is criticised that the detectable pKRAS is merely a surrogate for a high ctDNA level. However, KRAS was detected even in patients with low cfDNA levels (data not presented). It is correct that we and others have reported that a high level of total cfDNA implies a poor prognosis in itself (Spindler et al, 2012,2013a, 2013b, 2013c, 2013d; Hansen et al, 2014). Clearly, we have also observed a strong correlation between total cell-free DNA levels and quantitative mutated alleles. In the present report, we did not present the quantitative data of total cfDNA levels (data are submitted for publication elsewhere), but in brief, previously combined analysis suggests that the combination of both parameters has a strong clinical impact, indicating that the presence of KRAS does not merely reflect a high level of cfDNA. Furthermore, the potential utility of plasma KRAS detection with the present method should not be disregarded on the basis of biological assumptions, but rather validated in larger cohorts. For clinical purposes, a simple detection of mutations in a sample is feasible compared with the broad quantitative range that cfDNA measurement provides and makes a clinical application difficult.

The authors comment on the role of mutations for 'acquired resistance' to EGFR inhibition. We and others have indeed presented data that suggest that mutations appear at the time of progression (Diaz et al, 2012; Misale et al, 2012; Spindler et al, 2012; Tougeron et al, 2013). Clearly, optimal methods need to be applied with the perspective of gaining further knowledge of tumour biology, heterogeneity and to clarify whether mutations are early events at low concentrations or de novo mutations actually do appear along with the development of resistance to a certain therapy.

In conclusion, we are pleased to be able to contribute to the discussion and call for international cooperation to gain further knowledge of methodological, biological and clinical aspects within this interesting field.

\section{REFERENCES}

Diaz Jr LA, Williams RT, Wu J, Kinde I, Hecht JR, Berlin J, Allen B, Bozic I, Reiter JG, Nowak MA, Kinzler KW, Oliner KS, Vogelstein B (2012) The molecular evolution of acquired resistance to targeted EGFR blockade in colorectal cancers. Nature 486: 537-540.

Hansen TF, Andersen RF, Pallisgaard N, Spindler K-LG, Pløen J, Keldsen N, Lindebjerg J, Sørensen FB, Jakobsen A (2014) A three weekly schedule of irinotecan and panitumumab as third-line treatment for patients with wild type KRAS metastatic colorectal cancer: Results from a phase II trial. Colorectal Cancer (in press).

Misale S, Yaeger R, Hobor S, Scala E, Janakiraman M, Liska D, Valtorta E, Schiavo R, Buscarino M, Siravegna G, Bencardino K, Cercek A, Chen CT Veronese S, Zanon C, Sartore-Bianchi A, Gambacorta M, Gallicchio M, Vakiani E, Boscaro V, Medico E, Weiser M, Siena S, Di Nicolantonio F, Solit D, Bardelli A (2012) Emergence of KRAS mutations and acquired resistance to anti-EGFR therapy in colorectal cancer. Nature 486: $532-536$

Spindler K, Pallisgaard N, Andersen R, Ploen J, Jakobsen A (2013c) Pemetrexed and gemcitabine for chemotherapy refractory colorectal cancer-results of a phase II and translational research study. J Cancer Ther 4(6B): $44-50$

Spindler KG, Appelt A, Pallisgaard N, Andersen R, Jakobsen A (2013a) KRAS mutated Plasma DNA as predictor of outcome from irinotecan monotherapy in metastatic colorectal cancer. Br J Cancer 109: 3067-3072.

Spindler KL, Pallisgaard N, Andersen RF, Ploen J, Jakobsen A (2013b) Gemcitabine and Capecitabine for heavily pre-treated metastatic colorectal cancer- A phase II and translational research study. Anticancer Res 34(2): $845-850$.

Spindler KL, Pallisgaard N, Vogelius I, Jakobsen A (2012) Quantitative Cell Free DNA, KRAS and BRAF mutations in Plasma from Patients with Metastatic Colorectal Cancer during Treatment with Cetuximab and Irinotecan. Clin Cancer Res 18(4): 1177-1185.

Spindler KL, Sorensen M, Pallisgaard N, Andersen R, Havelund BM, Ploen J, Lassen U, Jakobsen A (2013d) Phase II trial of temsirolimus alone and in combination with irinotecan for KRAS mutant metastatic colorectal cancer: outcome and results of KRAS mutational analysis in plasma. Acta Oncol 52(5): 963-970.

Spindler KL, Pallisgaard N, Andersen RF, Jakobsen A (2012) Changes of mutational status during third line treatment for metastatic colorectal cancer. EMCC The 6th European Multidisciplinary Conference on Colorectal cancer. Pragh April 15-17 2012. Oral presentation.

Tougeron D, Lecomte T, Pages JC, Villalva C, Collin C, Ferru A, Tourani JM, Silvain C, Levillain P, Karayan-Tapon L (2013) Effect of low-frequency KRAS mutations and response to anti-EGFR therapy in metastatic colorectal cancer. Ann Oncol 24: 1267-1273.

Tougeron D, Laurent-Puig P, Zaanan A (2014) Comment on 'KRAS-mutated plasma DNA as predictor of outcome from irinotecan monotherapy in metastatic colorectal cancer'. Br J Cancer 111(12): 2379-2380.

*Correspondence: K-LG Spindler; E-mail: k.g.spindler@rm.dk

${ }^{4}$ Current address: Department of Oncology, Aarhus University Hospital, Aarhus, Denmark

Published online 11 March 2014

(c) 2014 Cancer Research UK. All rights reserved 0007-0920/14

http://creativecommons.org/licenses/by-nc-sa/3.0/ 